\title{
Managing brand presence through social media: the case of UK football clubs
}

\section{Abstract}

Purpose - This research contributes to knowledge on the issues and benefits associated with managing brand presence and relationships through social media. UK football clubs are big businesses, with committed communities of fans, so are an ideal context from which to develop an understanding of the issues and challenges facing organisations as they seek to protect and promote their brand online.

Design/methodology/approach - Owing to the emergent nature of social media, and the criticality of the relationships between clubs and their fans, an exploratory study using a multiple case study approach was used to gather rich insights into the phenomenon, from the club perspective.

Findings - Clubs agreed that further development of social media strategies had potential to deliver interaction and engagement, community growth and belonging, traffic flow to official websites, and commercial gain. However, in developing their social media strategies they had two key concerns. The first concerned the control of the brand presence and image in social media, and how to respond to the opportunities that social media present to fans to impact on the brand. The second concern was how to strike an appropriate balance between strategies that deliver short term revenue, and those that build longer term brand loyalty.

Originality/value - This research is the first to offer insights into the issues facing organisations when developing their social media strategy.

Keywords: social networking; relationship marketing; football; social media.

Article Classification - Research paper

\section{Introduction}

Social media sites have become an important digital meeting place for friends and acquaintances, and their reach has grown significantly in the last few years (Halliday and Vrusias, 2011; Harrigan, 2011). Social media is a broad term often used to encapsulate the applications that enable increasingly popular social activities, such as blogging, micro-blogging, social networking, photo-sharing and video-sharing (Centeno et al., 2009). For example, the UK Facebook population reached 30.1 million as of July 2012 (Checkfacebook.com, 2012) whilst UK Twitter UK profiles have grown to 23.8m (The Social Media 
Today, 2012). Twitter follower statistics for English Premier League (EPL) clubs total 8.5 million as of March 2013 (Digital-Football.com, 2013).

In this article social network sites (SNS) are defined as: “...web-based services that allow individuals to (1) construct a public or semi-public profile within a bounded system, (2) articulate a list of other users with whom they share a connection, and (3) view and traverse their list of connections and those made by others within the system."(Boyd and Ellison, 2008:211). Regarding the broader term of social media, it is recognized by Kaplan and Haenlein (2010) that no clear definition or categorization of applications and sites such as Facebook and YouTube exists. They define social media generally as "a group of Internet-based applications that build on the ideological and technological foundations of Web 2.0, and that allow the creation and exchange of User Generated Content.” (2010:61). This paper addresses the management of brand presence within the social media channels of Facebook and Twitter specifically. However, given that academic attention has only very recently addressed social media, the literature review incorporates the relatively more established field of SNS. Hence, use of extant literature incorporates studies that refer to SNS and social media in order to better understand the theoretical developments in this domain.

The aim of this research is to examine the issues faced in relation to social media strategy development, in the context of UK football clubs. Given the very limited previous research into the management of social media presence, it is anticipated that this research will have relevance and transferability beyond the specific sector in which the research is conducted. Specifically the objectives of this research are to:

- Gather insights into the issues that football club management perceives in relation to developing a social media strategy.

- Develop an understanding of football club management's perceptions of the potential benefits to be realized through developing effective social media strategies.

Social media are increasingly being viewed as an additional marketing channel through which businesses can communicate or interact with their customers and prospective customers (Gummerus et al., 2011). However, there is evidence that users of social media sites do not always welcome input from businesses, viewing this as commercial intrusion into their social space (Boyd and Ellison, 2008). On the other hand, Blackberry and Apple are examples of successful brand presence utilising social media (Harrigan, 2011). The size of the potential audience, plus the level of interactivity available in 
general social media channels such as Facebook and Twitter, invites businesses to assess how this may be achieved. Accordingly, there is considerable interest in the approach that businesses in different sectors take to the management of their social media brand presence (Gummerus et al., 2011). Consistent with this there have been various calls for further research into the commercial use of social media sites such as Facebook, YouTube and Twitter, to contribute towards the development of a theoretical foundation for marketing and brand building in this arena (cf. Beer, 2008; Fuchs, 2009; Gummerus et al., 2011; Hennig-Thurau et al., 2010).

This research focuses on social media strategies adopted by UK football clubs. This is an informative and appropriate setting for a study on the management of brand presence and engagement with and the cultivation of online communities through social media for a number of reasons. First, football is big business, both nationally and often internationally. The latest report into football finance (Deloitte, 2012) shows the top 20 clubs earned $€ 4.4$ billion in combined revenues (2010/11). In the same period, EPL average club revenues rose to $£ 114 \mathrm{~m}$, totaling $£ 2.27$ billion. Football League (FL) clubs achieved a total of $£ 6.3$ billion in combined revenues. Second, football clubs have strong fan bases, which contribute to their success through brand support and commercial transactions. Further, these fan bases embed a wealth of complex community relationships, often demonstrating enduring loyalty to the club (Supporters Direct and Substance, 2010). Third, football-related content is a major driver in the growth of online discussion; in 2012 football was one of the dominant UK Twitter trends. (Telegraph, 2012). Finally, unofficial football websites have grown considerably in popularity in recent years. For instance, rather than using official club sites, $23 \%$ of Championship club fans are utilizing unofficial sites as their main source of information (SportsWise, 2010). Another characteristic of this sector that needs to be taken into account is that most professional UK clubs have their website hosted and managed via the Football League interactive (FLi) network, and the constraints imposed on clubs by the FLi agreement have the potential to inhibit the speed of any innovation in clubs' use of social media. Being run as a managed portal, standardization of participating club website presence ensures consistency but makes individual innovations to site structure to be rolled out across the network difficult.

The paper is structured as follows. First, a literature review on social media, the effect of social media on brands, and managing relationships and communities in football, is provided. Next, the qualitative, case-based method is outlined. The findings and discussion section then presents and discusses the issues and potential benefits of social media engagement for football clubs. Finally, the conclusions and 
recommendations summarise the findings from the research and suggest implications for management and opportunities for future research.

\section{Literature Review}

\section{Social media}

The emergence of social media technologies and sites, and their rapid rate of adoption has triggered recent, yet growing academic discussion. Perspectives in previous research range from those focused on their application (cf. Beer, 2008; Constantinides and Fountain, 2008; Kaplan and Haenlein, 2010) to those offering a historical perspective on the key changes and associated activities concerning SNS (Boyd and Ellison, 2008).

Early research demonstrated that such online communication channels offer potential for providing useful information for commercial purposes (Beer, 2008; Halliday, and Vrusias, 2011; Harrigan, 2011). However, social media users are not averse to switching to competing sites if they perceive excessive commercial influence being used (Boyd and Ellison, 2008). This reinforces the warning that traditional marketing approaches should not be replicated in the social web (Mitchell, 2008). Early research, specifically in the football sector has shown that adopting the prevailing mindset of trying to control user-generated content does not engender trust between fans and club owners (McLean and Wainwright, 2009). Hence, the current transaction-oriented relationship marketing activity of football clubs (Adamson et al., 2006) is unlikely to engender support where fans post football-related content, via interactions online (Gibbons and Dixon, 2010) including commercialization of the relationship. This study attempts to offer some insights into the question of whether practitioners are willing to cede control to consumers in the post-internet era (Christodoulides et al., 2009).

Contributions from the more established literature on online communities suggest that empowering customers is crucial to online relationships (Thorbjørnsen et al., 2002) and a very powerful approach in community building (Rowley et al., 2007). Sports fans have been found to have extremely high product involvement (Mullin et al., 2007), and may be particularly likely to exhibit signs of tribal behaviour, centred on consumption-related interests (Kozinets, 1999). In this study, a tribe is defined as: "a network of heterogeneous persons...who are linked by a shared passion or emotion; a tribe is capable of 
collective action, its members are not simple consumers, they are also advocates;" (Cova and Cova, 2002:602). For football fans the link is the club (Dionisio et al., 2008).

\section{The effect of social media on brands}

According to Shang et al. (2006), experiences in a virtual community, such as a social media site, may be a significant part of the consumer experience of a brand. In particular, since opinions communicated between members of a consumer community (Hennig-Thurau et al., 2004) can be regarded as a form of electronic word of mouth (eWOM), they may impact on customers' attitudes and behaviours. In a recent review of eWOM, Chan and Ngai (2011) found that out of almost 100 papers none had covered the management view in depth. Thus, research in this area is both timely and necessary from a marketing and brand management perspective. Even before the advent of widespread use of social media, there was a recognition that virtual consumer communities might become threats to companies, because companies have no control over negative messages from unsatisfied customers on the Internet (Maclaran and Catterall, 2002; Muniz and O’Guinn, 2001). More recently, various commentators have suggested that social media are shifting the balance of power in relation to the brand from the organisation to the consumer (Bernoff and Li, 2008; Fisher and Smith, 2011), and that command and control branding will not be tolerated online (Christodoulides et al., 2009). According to Christodoulides et al. (2009), postinternet branding is about facilitating conversations around the brand, and the co-creation of meaning. Consumers have been empowered to comment on their experiences with and opinions of a brand, and if they choose, to tell a different story about the brand to that which the brand owners seek to disseminate. This means that company push and commercialisation may not be tolerated in social space, thus creating a serious issue for brand owners wishing to commercialise social sites and control brand communications online.

Accordingly, researchers and practitioners have started to turn their attention to how marketers can engage in social media. In a relatively early opinion piece, Drury (2008) foresees a future in which social media will provide brands with one of the most personal, trusted and direct points of access to consumers, and recognises the need for brands to begin testing the medium. In a recent study across three different sectors, Bruhn et al. (2012) examine the relative impact of social media and traditional media in brand equity creation. Their findings suggest that both traditional communications and social media communications have a significant impact on brand equity, but that their contributions are different. Social media influence brand image, whilst traditional media have a stronger impact on brand 
awareness. Further, firm-created social media communication has an important impact on functional brand image, whereas user-generated social media communication exerts a major influence on hedonic brand image. Whilst further research of this nature would be valuable, this study offers an early indicator that organizations need to understand the relative impact of traditional and social media on brand equity. Three other studies are also worthy of mention, because they make useful contributions on aspects of the management of the brand in a social media context. Shang et al. (2006) explored the value of lurking and posting on brand loyalty in a community of Apple computer users in Taiwan. Perhaps surprisingly, they found that lurking contributed to brand loyalty more than posting did, because the primary purpose of lurking was to find information on product function/performance. De Vries et al., (2012) examine the popularity or acceptability of brand posts on brand fan pages. Perhaps most intriguingly, Fisher and Smith (2012) advocate a mindset to embrace "predictable unpredictability" (p.347) when marketers are dealing with decentralized brand-related communications. This, they claim, demands a serious rethink of many established tenets of branding and marketing theory. The wider understanding of (1) the issues and, (2) the impact of social media engagement in the football sector have yet to be explored in the context of sport in general and football in particular from a brand owner perspective.

\section{Managing relationships and communities in football}

It is important to note football fans are not considered typical of most customers. In following a team, the relationship involves much more than transaction-based customer relationships (Healy and McDonagh, 2012). Being a fan involves 'doing' something (Richardson, 2007), such as evoking a shared sense of emotional attachment to their club (Abosag et al. 2012). In both physical match day environments and online communities, fans co-create their experiences through utilising flags, banners and songs (Healy and McDonagh, 2012), in addition to exchanging information regarding club traditions, myths and symbols (Pongsakomrungsilp and Schroeder, 2012). For many fans, their clubrelated consumption is, to varying degrees, part of their self-identity (Tapp and Clowes, 2002). Fans, as customers, therefore exhibit social and cultural attachment to clubs (Supporters Direct and Substance, 2010), which is increasingly common on a global scale as internet growth continues to shape fandom (Gibbons and Dixon, 2010) for major teams in particular (Nash, 2000).

It is suggested there is a strong sense of community amongst sports and football fans (Sweeney, 2010; Underwood et al., 2001), with sports fans having a unique relationship with the team they support (Bühler and Nufer, 2010; Chadwick and Beech, 2007). Most professional UK clubs originated in their 
local communities, hence their ethos had never been to maximise profits (Sir Norman Chester Centre for Football Research, 2002). This creates a level of tension between fan and club in relation to the level and focus of communications about the football brand. Given the ease of two-way communications online and the restrictions imposed by the FLi - this creates a dichotomy for both the fan and the club. In the current climate clubs face very difficult conditions (Deloitte, 2009) as they allow spending on wages to undermine financial sustainability (Deloitte, 2010). In this context, existing academic research has been critical of sport marketing activity. The more recent climate of commercialism is argued to be in danger of breaking the historic link between club and its fan community (Chadwick and Beech, 2007; Chadwick et al., 2008), in part because of the sensitivities of football fans and how they perceive clubs to be commercialising the club-fan relationship..

Although commitment, involvement, shared values and trust are suggested as related to sports fan attitudes and behaviours (Bee and Kahle, 2006), there is generally a distinct lack of research into the understanding of relationship marketing theory in the context of the sport industry (Bee and Kahle, 2006; Stavros and Westberg, 2009). Published research appears to have been influenced by the commitment-trust based theory of Morgan and Hunt (1994, p.22), which contends: "Relationship marketing refers to all marketing activities, directed towards establishing, developing, and maintaining successful relational exchanges".

Previous literature has examined loyalty and segmentation. For example, it was found that football fan attitudinal and behavioural loyalties are much more complex than the conventional wisdom of 'supporters for life' (Tapp and Clowes, 2002a; Tapp, 2004). Much agreement can be found between Tapp and Clowes (2002), who identified 'fanatics' as one example of highly involved football consumers, and Bee and Kahle (2006) who suggested how such fans display their commitment through repeat ticket purchase and a desire to demonstrate involvement through exhibiting certain behaviours (e.g. internalizing the values of the club). Their work was grounded in psychological theories and encouraged the consideration of different levels of trust and the impact on the relationship, based on the complex nature of sport consumer trust. In developing their functional model of relationship marketing in sport, they extended the notion of trust as a precursor to commitment (Bee and Kahle, 2006).

Beech et al., (2000) demonstrated the link between football club websites and relationship marketing, and found differing awareness levels of relationship marketing at football clubs. Since this time, 
however, there has been limited academic discussion about this topic despite changes in the market environment (Veloutsou et al., 2002) following the advent of social media. Concentrating on the fan perspective, McLean and Wainwright (2009) discovered fan dialogue on an unofficial club forum site for Newcastle United FC was restricted due to corporate interests and subsequent media manipulation, by the club itself. The club applying pressure on the site owners, to restrict unfavourable comments, only resulted in further alienation of already disaffected supporters. For football clubs, such trends represent a number of potential issues, for example potential loosening of the bond with fans, lost advertising revenues, and impaired relationship with fans.

\section{Summary}

The literature review demonstrates that whilst social media may present a suitable arena in which to promote customer relationships, build customer communities, and engage in communication with customers little is known about both the issues and the impact of social media in the football industry. Managed effectively, an organization's engagement in social media has potential to drive the generation of both commercial value and brand equity. However, one of the big challenges is that in social media, it is easy for customers, or in the sports world, fans, to contest control of the brand image, identity and values. This creates a strategic dilemma for brand managers who wish to optimize revenue generation and commercialization of the football brand whilst simultaneously strengthening fan relationships and avoiding disengaging fans and losing them to unofficial sites where they have little control over brand conversations.

In summary, the literature review presented in sections 2.1-2.3 identifies several over-lapping core themes in relation to issues of control, fan engagement and commercialization. In addition, it identifies a number of potential perceived benefits from employing social media strategy in terms of content, interaction, community and revenue generation. These factors are summarised in Figure 1; they informed the design of the interview protocol as discussed in the following section, and the analysis of the interview transcripts.

\section{Insert Figure 1 here}




\section{Method}

\section{Research design}

Since there is little previous research on the management of brand presence in social media, this study adopted an exploratory approach, based on multiple case study design. Case study research is increasingly common in football-related marketing studies; however, the majority tend to be single case (cf. Adamson et al., 2005; Tapp, 2004; Tapp and Clowes, 2002). This creates a need for more holistic studies which cover a wider variety of cases in the football context in order to build greater depth and richness into the incumbent knowledge base. Case research is firmly established in academic research into online communities and SNS but is limited in the context of social media where the majority of studies focus on quantitative surveys from the consumer perspective. Case study research is suited to evaluating the 'how' and 'why' questions of exploratory research in under-investigated areas (Yin, 2009) and multiple case research can lead to a genuine academic contribution (Eisenhardt, 1989). This paper uses four case studies in order to offer varied and richer empirical evidence (Eisenhardt and Graebner, 2007).

An effective social media strategy appears to be pivotal to the future success of clubs in the UK football sector. However, they have, for various reasons, been slow to engage with social media and as such research is currently limited. Accordingly, the UK football sector was selected because:

- Many of the football clubs in this sector are large businesses, with substantial fan bases (Deloitte, 2011; 2012), making this an exciting sector for studies into engagement within the context of relationship management given the increasing need for commercialisation as the football clubs wrestle with financial and revenue generation issues alongside globalization of the brand.

- Football clubs have communities, whose support is key to the success of the club and whose fans often have a longstanding loyalty to the club (Supporters Direct and Substance, 2010) making them an interesting site for brand management research.

- The extent of football-related content on social media sites, and the popularity of unofficial football websites suggests that football fans have embraced online community and communication (Silverman, 2010); and understanding the brand owner perspective will provide 
insight for future development of the official football brand in the face of increasing migration to unofficial sites and growing concerns over control of brand communications .

A case multiple study approach was adopted for this study. The advantage of the case study approach is that it investigates a contemporary phenomenon in its context (Yin, 2009). This approach is increasingly being viewed as a rigorous research strategy (Hartley, 2004). A multiple case design was adopted in this research because it offers an opportunity for richer and deeper analytical comparison. Stake argues that multiple cases are not chosen to support generalization, but rather because: 'understanding them will lead to better understanding, perhaps better theorizing about a still larger collections of cases' (2005:446). In this study four purposively selected clubs were deemed sufficient to generate new theoretical insights. Creswell (2007) warns that the more cases studies, the more the overall analysis is diluted.

\section{Case descriptions}

Table 1 offers a brief profile of each case, based on the desk research. The cases are considered exemplars of UK football clubs, predominantly drawn from the FLi network of over eighty UK football clubs. All of the case clubs were significant players in either the English Premier League (EPL) or the (UK) Football League. Clubs were selected to achieve diversity in their recent fates regarding league status, spectator attendance levels, and revenue. Case A is a large club in terms of attendance at matches, size of fan base, and revenue. In addition, it has experienced promotion to and relegation from the EPL. It makes some limited use of social media. Case B is a medium-sized club in terms of attendance, fan base, and revenue, and has also experienced a mix of promotion and relegation. Case B had no official social media presence on external platforms, such as Facebook. Case $\mathrm{C}$ also had no official social media presence at the time of research. Therefore, the gap created by a lack of official social media presence on Facebook and Twitter by cases B and C, was already being filled by fans setting up their own unofficial presence and gaining fans and followers. Both cases regarded this as a missed opportunity to be addressed. Like case $\mathrm{B}$, case $\mathrm{C}$ is also a medium-sized club, in terms of attendance and fan base, but has less of an international profile than A or B. Due to EPL status the club enjoys higher revenue than a club of similar size may expect. In terms of revenue, Case D is smaller than the other three clubs, but attendance and fan base are similar to Case C, although their fan base is more international. Case D resided in the second tier at the time of data gathering. It makes some minimal use of social media. In summary, in common with all EPL and FLi football clubs at the time of the research, every case was 
very much in the infancy of any social media presence or how to respond to the challenge of this new landscape.

\section{Insert Table 1 about here}

\section{Data Collection}

Data on the case study clubs was gathered through a combination of desk research, based on documents and websites, and semi-structured interviews with four senior managers who had responsibility variously for marketing, branding, and web presence. Desk research was undertaken in order to familiarize the researcher with the club and aspects of its online presence and, later, to confirm insights gained from the expert interviews. Desk research focused on: branded social media presence of the case study clubs (where this existed) unofficial social media sites related to each case; selected digital relationship marketing communications of the case study clubs; key newspaper and industry websites; and, key industry reports. The desk research allowed the authors to identify the business need for the research, in addition to reviewing current digital marketing communications from each club to identify if this matched the claims made in the interview data. Finally, the desk research provided a more informed view from which to evaluate the findings and subsequent discussion.

In addition, an inductive approach that used semi-structured interviews to generate qualitative data was used (Saunders et al., 2007). Whilst the research aim was to investigate issues faced in relation to social media strategy development, it was recognised that it was important to be open and to provide respondents with the opportunity to present their understandings. Consequently, although at one level the interviews could be viewed as 'fact gathering' exercises, there was also an element of gaining an understanding of the meanings that the respondents attached to branding, relationships and social media presence. Hence, the qualitative research design adopted, based on semi-structured interviews, provides in-depth insights, is flexible and exploratory (Bryman and Bell, 2011). An interview schedule was designed and piloted. The main sections in the interview schedule related to their concerns regarding social media. Interviews were recorded and transcribed; these were supplemented by field notes on the general feel of the interview and key points. All transcripts were approved by interviewees. Participant checking was used during the stages of transcript approval, initial coding, and key themes identified at within case-level to enhance validity. This form of 'member checking' adds rigour to the case research 
process (Creswell and Miller, 2000) given that it is the "most useful technique for establishing credibility" in qualitative research (Lincoln and Guba, 1985:314).

Thematic analysis was performed on the interview transcripts. Within-case analysis preceded acrosscase analysis (Patton, 2002; Perry, 1998) in order to identify emergent themes, content and key issues related to the research aim. This foundation was later revisited with cases as a whole in order to “... allow commonalities to emerge" (Stavros and Westberg, 2009:312). Data analysis was completed manually in order to maximize researcher interpretation of the data. Closeness to the data allowed distinctive themes to emerge and encouraged detailed knowledge of each case (Eisenhardt, 1991). In vivo codes served as the key identifiers for each participant's meanings, which were later validated by each participant. The process used was therefore: (1) line by line analysis; (2) in vivo coding; (3) focused coding; and (4) theoretical coding. Interview analysis was informed by insights from desk research.

\title{
Findings and discussion
}

This section presents the findings of this study generated from the interviews with key informants and supported by insights from desk research.. First, the perceptions of club representatives regarding the issues associated with their club's engagement with social media are outlined. Next, attention switches to club representative's understanding of the potential benefits of engagement in social media. Findings are discussed in the light of previous literature. Overall, three main issues with social media and four key perceived benefits were identified in this study (see Figure 1).

\section{Social media strategy issues}

\section{Control of conversation}

Clubs were concerned about their control of conversations associated with the club, and also, ultimately in the brand identity and image.

\begin{abstract}
All interviewees recognized that conversation, sometimes in the form of 'banter', was a key element of football support, but they were uncertain as to how to manage, or more generally respond to conversations about the brand, especially those that were disseminated more widely through digital media. There was a particular concern about unfavorable comments about the club, or offensive language, and a shared awareness that these comments were being posted on unofficial websites, in social media sites, as well as being shared face-to-face. As one interviewee said:
\end{abstract}


"These supporters are saying it in the pubs, or on the terraces, or in the shops, wherever they meet and congregate. So denying them that space on the website doesn't mean that those views will go away." (Marketing Manager, Case C)

Others suggested that the nature of social media permitted such exchange and was hence the reason fans utilized unofficial sites. However, due to concerns regarding negative comments, there is a fear at club level of allowing supporter conversations within the official club website.

Clubs were concerned about the impact of social media on their brand, specifically reputation and brand equity and in the context of SNS are nervous about releasing control of the brand:

"People are talking to one another about the Club, about the brand, about what's going on." (Marketing Manager, Club B).

Clubs "...have just shied away from any level of interaction and engagement with our supporters." (Head of Customer Operations, Club A)

The responses of cases B and C above reveal some frustration at the current lack of official social media presence. Case A effectively summarises the lack of interaction from the brand on the official Facebook and Twitter profiles, which were simply being used as news feeds, duplicating content already on the official website. All interviewees suggested that football clubs had a very high brand loyalty in comparison to other sectors. Interviewees perceived brands to be associated with history and heritage, and felt that for the fans, the beliefs and values and what the brand represented were key to brand loyalty. It was suggested the tribal passion of fans towards their club brand was potentially very powerful. This is consistent with other researchers' views that fans can enact tribal behavior through their club link (Dionísio et al., 2008).

Notwithstanding their concerns regarding control, there was a general recognition that in order to tap into the passion of fans it is necessary to accept that views expressed by fans will not always be what the club wants to hear. Interviewees all discussed the need to release some control of the conversation if 
official sites are to accommodate and facilitate such fan debate, and were aware of the need to progress towards an understanding of appropriate controls.

Interviewees suggested a number of contexts in which control should be exercised. The first of these centred on the potential hijacking of the online conversation by rival club supporters. Such concerns are related to the tribal nature of football support (Dionísio et al., 2008; Tapp and Clowes, 2002) in addition to the social media response of such tribal fans, via collective action. Another area for control might be the attitude of fans towards the club chairman, manager, players or staff in general, which on occasion is likely to lead to more extreme negative comments being publicly posted. For example, Case B suggested this may result in potential sponsors not wishing to be associated with the club brand. This would naturally have an impact, therefore, on the opportunities for revenue maximisation in the context of commercialization (discussed later). Control is therefore closely linked with the openness of clubs towards fans and fan affinity with their club, from both a relationship marketing and loyalty perspective.

Finally, concern was also expressed regarding the management of and responsibility within clubs for social media content and engagement with fans. Presently, any monitoring of social media by each case is ad hoc and covert. For all cases, the potential cost of formally allocating resource to post and monitor genuinely engaging social media content via, for example, Twitter or Facebook were considered labour intensive and potentially costly for clubs. These findings concur with literature that alludes to the immersive nature of the experience of interaction and community involvement on such sites as Facebook and Twitter (Keenan and Shiri, 2009) which were those specifically mentioned by clubs as their primary source of social media communication. Finally, consistency of message was cited as something that needed to be managed in order to maintain fan engagement and ensure a more effective fan experience.

However, on the positive side all cases were slowly moving away from the lack of transparency in their dealings with fans, to a degree of openness. For example, Club A talked of moving from "building gangways" to a new approach of collaboration with fans which was being considered as an option to engage in social media activity more proactively. The difficulty for clubs was knowing to what extent they can trust fans to refrain from abusive or offensive dialogue in any official social media provision. Criticism of clubs suggests they need to be much more open in appreciating their value as a "social business" with emphasis on their impact on the local community and stakeholders (Supporters Direct 
and Substance, 2010:4). However, all four cases were found to be increasing their level of openness.

Overall, clubs are concerned about control over conversations with regard to the brand and recognise that resolutions to this issue will need to be embedded in any social media strategy. This may be because they perceive themselves as owners or guardians of the brand, and the situation is captured in the following quote:

"The value of a brand belongs to the market, and not to the company... the management is not prepared for dealing with the brand, it is because in their mind-sets they are managing a closed structure that is the company. The brand is an open structure - they don't know how to manage an open structure." (Guimaraes, 2007:79)

In order to move forward clubs need to develop a culture in which there is a perception of co-ownership of the brand, alongside a recognition of mutuality of benefits from a strong brand presence and the part that fans play in this process..

\section{Fan engagement}

Nervousness regarding control of the brand in social media may well be grounded in the lack of success that football clubs have had previously in engaging with or even understanding their fans through digital means. For example, interviewees reported that a lack of systems integration and data warehousing contributes to a limited view of customer behaviour and a fragmented approach to relationship marketing communications

“...we have a single customer view of some sort which is still very much in its embryonic stage...our email providers aren't plugged into that single customer viewpoint yet... Did they click through on the email, did they shop off-site, did they browse around the site, how much did they spend online... you know we don't capture any of that information at the moment and that... isn't plugged into that central database...."(Head of Customer Operations, Case A)

Overall, there was a sense that there was no real effort to know the customer. This is consistent with previous research that suggests that demands for customised products and services are not being provided via club websites or electronic communications (Kriemadis et al., 2010). 
All clubs repeatedly revealed the current official site (e.g. www.nufc.co.uk) provision to be lacking engagement and interaction as a major concern. Their worry was this is already causing fans to migrate to unofficial sites (e.g. www.nufc.com, or www.skysports.com) and that the "next generation" of fans were possibly seeking other forms of entertainment. For example, clickstreams for July-September 2010 of case D show that after leaving the official site, 11\% visit Facebook, 9\% visit the unofficial club forum and $2.3 \%$ migrate to Twitter. In addition, $6.4 \%$ of users have visited the unofficial club forum prior to arriving at the official site (Alexa.com, 2010). The need for clubs to engage with potentially discontented fans has already been expressed (Chadwick et al., 2008) otherwise they will develop a preference for alternative unofficial sites (SportsWise, 2008; Boyd et al., 2010). Clubs appear concerned that the lack of engagement through their current website triggers fans to migrate to unofficial sites, thus limiting their ability to manage the customer relationship online. This is consistent with Beech et al. (2000), who also showed a low level of traffic to official web sites. Indeed, links were made by the clubs between the lack of engagement, the weakness of the weekly 'push' communications and the frequency of website visits.

The lack of success in the realms of customer relationship management, and website traffic, has quite likely led to a lack of genuine action in response to social media. References to clubs "missing a trick", "playing at it" and "scratching the surface" were evidence of a reticent approach.

"... from what I've seen of it in the rest of the football industry I'm not convinced anybody is doing it particularly well. When you look at other industries and other uses of twitter particularly (yes) I think that we're miles behind." (Head of Customer Operations, Case A)

Adoption of social media was certainly hindered by the presently held belief at club level, that social media is a "fad" or "bandwagon", and some associated scepticism as to the figures and longevity of social media platforms such as Facebook and Twitter. A lack of any branded social media presence for cases $\mathrm{B}$ and $\mathrm{C}$ confirmed the reluctance at club level to embrace the opportunities for community engagement. The branded pages and profiles for Cases A and D clearly evidenced content that simply duplicated official site news, rather than being focused on engaging with the fan community. On the other hand, there was an acknowledgement that to continue doing very little, or nothing at all, was no longer an option. Thus, although the particular platforms mentioned may indeed lack longevity, the 
findings mirror the assertion that consumers will continue to actively use interactive two-way communications technologies (Fisher and Smith, 2011) whether or not clubs are involved. This places greater emphasis on the club owners to develop planned strategy in this area of brand management.

\section{Commercialisation}

The third key theme related to the achievement of commercial benefits through social media. Principally the use of social media was seen as a driver of traffic to the official site which is monetised via advertising revenue and sales of commercial products, such as online player TV, ticketing and merchandise. This approach is at least partially due to the club's desire to attract and retain more traffic to the official website, which also has consequences in terms of opportunity cost in the context of globalised football (Madeiro, 2007) and global football fandom (Sport Markt, 2009; Nash, 2000).

The theme of engagement demonstrated how clubs have been slow to respond hence they are now playing catch up. Their accepted problem now is to not be seen to be attempting to dominate the space by replicating rolling out the highly monetised model of their existing official website provision into branded social media environments:

"And that's probably the main difficulty - the corporatisation of these personal spaces." (Head of Customer Operations, Club A)

"... the danger is that you make it overtly commercial. That's the big, big issue." (Marketing Manager, Club C)

"We have to be a little bit careful that we don't push them [fans] into finding information elsewhere in terms of the stuff we put out from a Club point of view." (Marketing Manager, Club D)

The commercialism of football has been widely researched (cf. Bridgewater and Stray, 2002; Chadwick et al., 2008; Gibbons and Dixon, 2010; Harris and Ogbonna, 2008; Supporters Direct and Substance, 2010). The findings in this research appear to suggest that clubs are aware fans may consider social media as their space (private or public), yet there is pressure to use them as a commercial space (Beer, 2008) if they are to allocate resource. 
Ultimately, it is understandable that football clubs are concerned with revenue generation, but they need to develop a perspective on the web presence (that pervades their website and any social media engagement) that goes beyond revenue generation to a more sophisticated approach to brand building.

\section{Perceived benefits of social media}

Despite their tardiness and concerns regarding their engagement with social media, all interviewees acknowledged that there were benefits that their club might accrue from an effective social media strategy.

\section{Content}

As a result of the commercial agreement with FLi and its reliance on advertising revenue, driving traffic to the official site is the major objective of each club. Twitter may therefore offer the best immediate potential for clubs as it "... has proven to be a fantastic source of traffic for content driven sites, and the media companies with a strong presence on the service are using it to great effect...." (Hitwise, 2009). Accepting a need to do something, clubs A and D have activated a Twitter profile, though it was acknowledged these are duplicating the current news feeds of the official site. All cases recognised their current presence, or lack of presence, on Facebook or Twitter demonstrates they are playing with at social media at best.

"You can tick the boxes of web 2.0 but we're not really doing anything with it." (Head of Customer Operations, Case A)

Desk research of the branded Facebook pages and Twitter profiles for cases A and D confirmed that no unique content is being posted. It was simply duplication of existing official website headlines and links back to those full stories on the respective official sites. Used more imaginatively and effectively, the value of Twitter is proven in driving traffic back to the sites responsible for the original tweet, in addition to facilitating extensive (viral) re-tweeting (Kwak et al., 2010). This means that clubs who fail to engage with customer pull, and resist the move to social media, are potentially limiting the development of the brand and missing the opportunity to build brand equity and drive revenues for the club. Avoidance of fresh and original content is also likely to lead to further customer attrition from official sites and to limit the opportunity for enhancing relationship ties with the fan base. 


\section{Interaction}

In a link with tribal literature (Cova and Cova, 2002; Dionísio et al., 2008), all clubs identified that the way to drive traffic was to engage fans through their passion for the club. Football is tribal in nature (Tapp and Clowes, 2002) and all interviewees considered football to be unique in its ability to create a unifying interest around a team brand, recognising the positive manner in which sports consumers are involved with the product (Mullin et al., 2007). The key to this was considered to be the enabling of engagement in a proactive manner, rather than simply responding to discussion or duplicating existing official site content. Clubs hope this would overcome the limitations of their current generic 'push' communication, despite the absence of targeted and appropriate communications. It was suggested that social media offered real-time customer insight, enabling more sophisticated relationship marketing activity. The findings therefore suggest the commercial gain potential of social media in the football sector (Beer, 2008). Interviewees articulated an intuitive understanding of the benefits of engaging with online communities that exist around their club in the form of social media. The findings are congruent with the notion of creating value in brand communities through engagement (Schau et al., 2009).

\section{Community}

Interview responses regarding offering fans a chance to show their 'badge of honour' could be argued to be linked to the community engagement practices categorised in brand communities (Schau et al., 2009). Moreover, fans being given the opportunity to share experiences and credibility could be considered "impression management practices" (Schau et al., 2009:34). The findings revealed that clubs are considering "social media practices" by allowing fans to connect with fellow supporters in a specific location. One club suggested that the fan club branch Chairman could act as a facilitator in community growth and belonging.. Also, regarding match day experience, clubs have already been willing to successfully respond to concerns raised in discussions on unofficial social media sites, not by participating in the conversation but by introducing initiatives at the stadia. Going further, despite having no branded presence, one club has openly used an unofficial fan community to ask for suggestions regarding the use of social media to enhance the match day experience, but has been reprimanded by fans for being too commercial in their interpretation of the suggestions made. These

findings reinforce clubs' concerns regarding social media strategy, branding and the theme of commercialisation. 
Revenue generation

The opportunity for clubs lies in attracting higher and more frequent traffic in order to improve page impressions on the official site, hence increasing revenue streams.

"As you get used to people's user habits and their profile of who they are you can get even more sophisticated. So I think that's how you commercialise the [social media] element. But it's the club shop window and if people are only passing once a week, then you've got a 1 in 7 chance of making a sale. If they're coming on 5 of 6 times a week, that has surely got to uplift your opportunity." (Marketing Manager, Club C)

Clubs also recognised the likelihood of social media advertising revenue arising from any potential adoption of social media into the template FLi web provision. The approach of the associated partners would likely result in a focus on driving advertising on club branded social media, at the expense of a stronger opportunity to engage with fans. This is evidence of the potential capital interests offered by social media (Beer, 2008). Despite the current lack of social media provision on official club websites via the FLi agreement, analysis uncovered the changing response of clubs to social media, mostly out of necessity and the need to respond to the needs of a more sophisticated fan base. Comments were consistent with the findings of other studies that revealed a wider demographic of football fans (SportsWise, 2008; 2010), as well as a more sophisticated customer-base with higher expectations of their online experience.

\section{Conclusions and recommendations}

\subsection{Summary}

This exploratory research set out to understand the attitudes of UK football clubs towards managing their brand presence in social media. Previous literature has highlighted the closed approach football clubs have to business and to control over their brand (McLean and Wainwright, 2009; Supporters Direct and Substance, 2010). In contrast, findings from this study reveal that although clubs have been slow to develop social media strategies, they are beginning to recognise that "this 'mind cuckoo' approach to branding that regards customers as passive recipients to brand value has no place in Web 2.0" (Christodoulides, 2009:142). Clubs are recognising that appropriate social media engagement has 
the potential to enhance their brand, in the arenas of content, interaction, community, and revenue generation. Indeed, these four foci are relatively consistent with the model of the four pillars of ibranding proposed by Simmons (2007). Simmons suggests that building brand equity in the Internet environment is dependent on the four pillars of marketing communication, understanding customers, content, and interactivity, and the interaction between the pillars. However, this research advances this model because it is based on a context in which there are existing fan communities, within which communications about the brand can take place, whether or not this is facilitated by the football club as brand owner. This is increasingly going to be the case for many other brands as social media give communities and customers an easier way of making their voice heard. In this context, content remains important for attracting people to a site, but interactivity is insufficient - organisations need to proactively seek to use interactivity as a basis for beneficial interaction. Interaction embeds both interactivity and marketing communication. In addition, 'community' goes one step beyond understanding customers to building and maintaining a relationship with customers and facilitating the maintenance of relationships between customers. Finally, revenue generation does not explicitly feature in Simmons (2007) discussion; this study however, demonstrates that football clubs, and arguably many other organisations are not only interested in using social media to build their brand equity, but also to generate more immediate and tangible revenue streams.

More generally, clubs are still wrestling with the issue of control over their brand. Given the importance of brand equity, it is likely that many other organisations will be wrestling with the dilemma of achieving consistency in brand messages and identity when others are empowered to discuss their brand. According to the emerging theoretical debate regarding branding in the post-Internet era, rather than still wishing to be the guardian of the brand, managers should facilitate and host brand-related dialogue by ceding control to customers (Christodoulides, 2009). Indeed Fisher and Smith (2011, p.345) conclude brands need to "let go" if they are to hold on to their customers. It is claimed companies only adjust their approach when consumers compete in some way. This study demonstrates that clubs are an example of major sporting organisations having some way to go before they are prepared to fully embrace the call for marketers to move away from centralized marketing activity. Although they are to some extent beginning to recognise that complete command and control branding will not be tolerated online (Christodoulides, et al., 2006), clubs are still mulling over the issues associated with the development of a social media strategy. They are considering the relative merits of engaging through social media in relation to the functionality of their official website, or through their engagement with or response to 
comments on unofficial websites. They recognise that fans and others will talk about their club, and in this digital age much of this conversation will occur in online channels. Further, some comments posted by fans and others may be offensive or make negative comments about the club, and might potentially damage the club's brand. Even more fundamentally, as Li and Bernoff (2008) suggest, Web 2.0 applications are shifting the balance of power from the firm to the consumer. Accordingly, clubs have no choice but to acknowledge fan's stake in the brand and therefore face two major issues:

1. How to work with fans to sustain and develop the brand so that it can flourish and deliver in the interest of all stakeholders.

2. The level and nature of the engagement that they choose to have with fans in social media, and the extent to which that engagement is on unofficial sites or the official club site.

The other key issue concerns the objectives of clubs' web presence. Their current experience of online presence is based on club websites supported by FLi, whose primary purpose is revenue generation through advertising, merchandising and other financial transactions. This gives them a predisposition towards looking for social media to drive traffic to the club website to support revenue generation. This study therefore reveals a different view to that discussed in the extant literature: that of the value of online brand communities as domains in their own right .

Accordingly, clubs have to revisit the long-standing tension between commerce and community that is an inherent characteristic of football clubs and other organisations with large and committed customer bases and consider:

3. The objectives of their social media engagement, especially in terms of the balance to be struck between seeking short term revenue generation or longer term cultivation of brand communities, and in turn, brand equity.

4. How to achieve a level of commercialisation of the web presence that both achieves the commercial objectives of the club, whilst designing a web presence that also meets the needs of fans, and other key stakeholder groups. 


\subsection{Contribution to theory}

This study has highlighted the potential impact of social media on brand management. It suggests the need not only for new approaches to the practice of brand management, but also to the dominant theoretical rhetoric of brands and branding which is grounded on the assumption that businesses own and can control their brand. This study provides empirical evidence to support those commentators who have suggested that social media are shifting the balance of power in relation to the brand from the organization to the consumer (Bernoff and Li, 2008: Christodoulides et al., 2009; Fisher and Smith, 2011). As suggested by Fisher and Smith (2012), this has a whole raft of consequences for both branding and marketing theory. For example, in the social media era in which both 'customers' and 'organizations' co-create meaning the traditional distinction between brand image and brand identity is called into question. In addition, it may become increasingly difficult to differentiate between brand communications, public relations and brand evaluation, as customers assert their right to both promote and criticize a brand through channels in which they can reach, in some instances large and international audiences. Finally, such developments may invite re-consideration of the pivotal concept of brand equity, to encompass the value delivered by a brand not only to the organization, but also to its customers.

\subsection{Limitations and recommendations for further research}

This study resonates with the views of other commentators and researchers who suggest that brands need to be managed differently in the digital space, and contributes to consideration of the issues and options facing organizations as they seek to manage their brand presence in social media. Nevertheless, it has a number of limitations that should be addressed by further research. The study has been conducted in a specific sector and at a specific point in time. First, it would be useful to understand whether the insights generated in this study are relevant for other organizations, both in the sports sector, and in other contexts where organizations have a committed and enthusiastic fan, member or customer base. Second, in the context of UK football clubs, the management of brand presence through social media is at a relatively early stage; our continuing, longitudinal, research in this area is likely to reveal how things unfold over the next few years. There is considerable scope for enhanced understanding of the way in which fans, members and customers will evolve their engagement with brands through social media over the next few years. Finally, it would be useful to conduct research that would provide insights into brand communications and engagement in social media in different countries and different cultures. This should extend beyond football to other sports, including, in particular those with 
associated fanatical supporters, such as American football and basketball, and to those developing countries that may have been slow adopters of the Internet, but are enthusiastic adopters of social media.

\subsection{Managerial Implications}

\section{Implications for Football clubs}

Football clubs need respond to the challenges and opportunities posed by social media. They should start the process by conducting an audit to assess the balance of the risks associated with continuing to do very little, and alternative strategies that may divert some of their marketing budget from other activities and require them to acquire new marketing philosophies and expertise. Based on the research reported in this article, these risks arise from fan conversations in both their own branded social media forums and in other social media spaces, particularly unofficial sites and other venues. So, initially, clubs need to 'listen' and participate in these spaces and make judgments about the value to be derived from a more fully developed strategy. They may legitimately have concerns about negative comments, brand hijacking, and tribal behaviour that is a potential embarrassment to the club. Equally, by not engaging in social media, they may be missing opportunities that a social media presence on their official website might provide for driving either or both of brand reputation and equity or revenue generation. The question is how valuable is a social media presence for the club?; the answer will be different for each club.

Those clubs that believe that investment in a social media strategy is worthwhile need to start by identifying the aims and objectives of such a strategy, and, in particular, its alignment with the club's wider marketing strategy. Next, they need to develop a range of tactics for managing the risks and reaping the benefits that can be derived from using social media to engage and interact with the fan community. Tactics are likely to include: search and sponsor links that drive traffic to a site; good quality, interesting and different content; opportunities for two-way dialogue; customization of content and communication to suit specific fan segments; and, opportunities to purchase highly valued merchandise. The underlying philosophy must be a meld of 'fan leadership' and public relations. Fan leadership is distinct from fan or customer understanding or engagement; it seeks to inspire and motivate a community. Fan leadership is based on understanding what fans might value in a social media presence, and working with fans to co-create and deliver the social media experience. Public relations is associated managing brand reputation, in the face of events, negative comments or reporting that have the potential to harm the brand and its organization. Social media are fast and merciless in generating 
and disseminating bad news; clubs need a strategy to guide their responses. This melded strategy of fan leadership and public relations will provide a foundation for both increased brand reputation and increased revenue generation.

\section{Implications for other organizations}

Whilst at first glance it may seem that football clubs are in a unique position, perhaps, at least in part due to their conservative approach to engagement in social media, the tensions that they face in respect of control of their brand in the social media era are shared by many other organizations, especially those with a strong membership or customer base that can be provoked to strong views about their brand. All such organizations need to recognise that they need an appropriate social media 'public relations' strategy in order to protect and promote their brand. In addition, they need to welcome, and cultivate member or customer contribution to building both the brand image and the brand experience. Finally,

they need to balance short-term revenue generation with longer term brand building through their web presence.

\section{References}

Abosag, I., Roper, S. and Hind, D. (2012) "Examining the Relationship between Brand Emotion and Brand Extension among Supporters of Professional Football Clubs", European Journal of Marketing, Vol. 46 No. 9, pre-publication article. 